\title{
PERFIL DA CONTAMINAÇÃO COM AFLATOXINA ENTRE EMBALAGENS DE PRODUTOS DE AMENDOIM ${ }^{1}$
}

\author{
Eduardo Micotti da GLORIA ${ }^{2, *}$, Alessandra de Cássia ROMERO ${ }^{3}$, Ana Paula Pereira CARVALHO ${ }^{3}$, \\ Maria Antonia CALORI DOMINGUES ${ }^{2}$, Priscila Vieira de Macedo GONÇALVES ${ }^{4}$
}

\begin{abstract}
RESUMO
Este estudo foi realizado com o objetivo de avaliar o perfil da distribuição da contaminação com aflatoxinas entre embalagens constituintes de lotes de confeitos de amendoim, expostos à venda no comércio. Os dados da distribuição da ocorrência e dos níveis de contaminação, aqui obtidos, sugerem que os procedimentos de amostragem, visando à detecção de aflatoxinas em produtos processados, sempre estarão associando um grau de incerteza muito elevado quanto à presença ou não e quanto ao nível médio de contaminação de um lote de produto processado. Entretanto, para melhorá-los, devem-se considerar as diferenças existentes entre os produtos com relação ao processamento ou não dos grãos que constituem sua matéria-prima, pois, em lotes de produtos em que a matéria-prima foi triturada ou moída, como por exemplo, o doce de amendoim do tipo paçoca, a distribuição da ocorrência e dos níveis mostrou um grau bem mais elevado de homogeneidade, quando comparado ao amendoim japonês que mantém a integridade da matéria-prima durante o seu processo de fabricação.

Palavras-chave: aflatoxina, distribuição, contaminação, amendoim, produtos processados amendoim.
\end{abstract}

\section{SUMMARY}

AFLOXIN CONTAMINATION PROFILE AMONG PACKAGES OF PEANUT CANDIES. This study was carried out to evaluate the profile of aflatoxin contamination distribution among packages of peanut candies trading. Aflatoxin occurrence and distribution date from this study suggest that sampling plans to aflatoxin detection in processed products are always associated with high degree of uncertain of presence or not and of the true average level of contamination. To improve sampling plans it is necessary to consider the differences among product types. There are processed products whose the raw material is grounded, like "paçoca" and other that it is not, like "amendoim japonês". Occurrence and distribution of aflatoxin contamination among packages in lots of "paçoca" was more homogeneus than in lots of "amendoim japonês".

Keywords: aflatoxin, distribution, contamination, peanut, peanut processed products.

\section{1 - INTRODUÇÃO}

A relação entre a presença de contaminação com aflatoxinas na dieta humana e o aparecimento de perturbações à saúde, como o câncer hepático [13, 21$]$, o kwashiorkor $[8,11]$ e a síndrome de Reye [4], já foi observada em certas populações. Certos pesquisadores, com base em dados toxicológicos existentes na literatura, classificaram as aflatoxinas como tendo capacidade de apresentar efeitos mutagênicos, teratogênicos e carcinogênicos [13]. O International Agency for Research on Câncer (IARC) classificou as aflatoxinas como uma substância natural que reconhecidamente pode causar câncer [12].

Diante da importância das aflatoxinas para a saúde humana, noventa e nove países estabeleceram limites máximos aceitáveis para sua presença em alimentos, rações e/ou produtos agrícolas [10].

\footnotetext{
${ }^{1}$ Recebido para publicação em 24/10/2005. Aceito para publicação em 6/7/2006 (001627)

${ }^{2}$ Depto. Agroindústria, Alimentos e Nutrição (ESALQ/USP),

Av. Pádua Dias, 11, CEP 13418-900, Piracicaba (SP),

E-mail:emgloria@esalq.usp.br

${ }^{3}$ Curso de Pós-graduação Ciência e Tecnologia de Alimentos (ESALQ/USP)

${ }^{4}$ Curso de graduação em Ciência dos Alimentos (ESALQ/USP),

* A quem a correspondência deve ser enviada
}

Contudo, a tarefa de detectar a presença de aflatoxinas em grãos é bastante difícil, uma vez que a contaminação é extremamente heterogênea. Pesquisadores encontraram [20], em um procedimento de checagem de contaminação de aflatoxina em lotes de amendoim, que a amostragem em um lote com nível de contaminação $20 \mathrm{ng} / \mathrm{g}$ foi responsável por aproximadamente $88 \%$ da variância total dos resultados. Com base em dados de contaminação com aflatoxinas para grãos individuais apresentados na literatura científica, que foram de $1.100 .000 \mathrm{ng} / \mathrm{g}$ para amendoim e de $400.000 \mathrm{ng} / \mathrm{g}$ para o milho, mostraram que lotes destes produtos poderiam estar com uma contaminação média de $20 \mathrm{ng} / \mathrm{g}$, quando apenas $0,0018 \%$ e $0,005 \%$, respectivamente, dos grãos destes produtos estivessem contaminados com os valores já relatados [9]. Em uma revisão sobre o desenvolvimento de planos de checagem de micotoxinas em alimentos e rações [6], foi ressaltado que uma atenção especial deve ser dirigida ao desenvolvimento de planos para produtos prontos para consumo, os quais refletem a distribuição de micotoxinas entre embalagens comerciais.

O processamento aplicado aos produtos agrícolas, que conservam a integridade dos grãos, tais como manufatura de confeito de amendoim tipo "japonês", em que há apenas a adição de cobertura aos grãos, podem não modificar esta distribuição heterogênea. Nos processos que desintegram os grãos destes produtos agrícolas e promovem a homogeneização das partículas geradas, tais como, a manufatura de doce 
de amendoim tipo paçoca, em que os grãos de amendoim são moídos e misturados com outros ingredientes, provavelmente se obtêm produtos com a contaminação mais homogênea e, portanto, com maior uniformidade de contaminação entre as embalagens do produto gerado. Contudo, mesmo para estes produtos, se for considerada a possibilidade da contaminação do produto após o seu processamento, durante a estocagem e/ou comercialização, novamente a contaminação pode apresentar-se no mercado individualizada por embalagens do produto, em que condições particulares, tais como, a atividade de água e temperatura altas, podem favorecer o crescimento fúngico e/ou produção de aflatoxinas.

Desta maneira, a amostragem de embalagens dos produtos, seja para controle de qualidade, para monitoramento no comércio ou estimativa de ingestão da toxina, deve ser realizada com bastante cuidado, com a finalidade de representar com maior segurança possível a verdadeira situação dos lotes de produtos comercializados.

O objetivo deste trabalho foi gerar informações sobre o perfil da contaminação de aflatoxinas entre embalagens de lotes de confeito de amendoim expostos à venda, considerando os produtos que continham o grão da matéria-prima (amendoim) íntegro e aqueles em que o grão foi triturado. Pois existe falta de informação sobre a distribuição da contaminação entre embalagens de um mesmo lote comercializado que está contaminado.

\section{2 - MATERIAL E MÉTODOS}

\section{1 - Amostragens}

Foram amostrados lotes do produto de amendoim denominado "amendoim japonês" e doce de amendoim tipo "paçoca". Treze lotes de amendoim japonês e dezenove de paçoca foram amostrados, totalizando 138 e 123 embalagens amostradas, respectivamente.

Os lotes dos produtos amostrados estavam expostos em diferentes estabelecimentos comerciais da cidade de Piracicaba - SP e foram amostrados também em diferentes períodos, durante os anos de 2002 e 2003.

Em cada ponto de venda, um ou mais lotes dos produtos, contendo embalagens com no mínimo $200 \mathrm{~g}$ e no máximo $1.000 \mathrm{~g}$, foram escolhidos aleatoriamente e o total de embalagens do lote exposto na prateleira foi contado, para proceder à sua amostragem.

A amostragem foi realizada coletando-se $20 \%$ das embalagens do lote exposto. Quando o total de embalagens do lote não era superior a 20 , foram coletadas, no mínimo, 3 embalagens.

\section{2 - Análise de atividade de água}

Visando caracterizar os lotes quanto à disponibilidade de água para crescimento fúngico no momento da amostragem, todas as embalagens coletadas foram avaliadas em laboratório quanto à atividade de água do seu conteúdo.
Para isto, as embalagens foram abertas realizando cortes horizontais e, preferencialmente, na região central ou superior frontal, retirando-se uma quantidade suficiente do produto para determinação.

As determinações de atividade de água foram realizadas com o aparelho marca TESTO, modelo 650. Todas as determinações foram realizadas em triplicata.

\section{3 - Análise de aflatoxinas}

A metodologia de extração das aflatoxinas seguiu os procedimentos preconizados por SOARES \& RODRIGUEZAMAYA [1989]. A detecção e quantificação foram realizadas em cromatografia em camada delgada (CCD). A cromatografia dos extratos de produtos derivados de amendoim foi realizada em placas bidimensionais, com co-cromatografia, para melhor identificação das aflatoxinas. A quantificação de aflatoxinas foi realizada na mesma placa pela comparação com padrões.

O desempenho analítico da metodologia e do analista, por meio da avaliação dos limites de detecção, quantificação, exatidão (recuperação) e repetibilidade em produtos de amendoim, foi testada ao se iniciarem as análises.

Para o teste de limite de detecção em cromatografia em camada delgada, foram feitas placas para visualização de diferentes e decrescentes níveis de contaminação com aflatoxina, adicionando-se, sobre o ponto de aplicação do extrato de uma amostra não contaminada, volumes decrescentes de padrão de aflatoxina. Entre as diferentes placas assim elaboradas, foi selecionada a placa em que o menor nível de contaminação pudesse ser, de forma inquestionável por três diferentes visualizadores, identificado. Este nível de contaminação foi considerado como provável limite de detecção. Uma vez que o menor nível a ser detectado em cromatografia em camada delgada é dependente de uma soma de etapas do procedimento analítico, desde a extração até a cromatografia, realizou-se a adição do equivalente ao menor nível de contaminação detectado na placa cromatográfica (provável limite de detecção), sobre amostras que não apresentaram contaminação. Este procedimento visou confirmar se o nível visualizado com a adição de padrão sobre a amostra em placa ainda seria visível, considerando o procedimento analítico completo e a soma de possíveis perdas de toxina durante esse processo. O extrato assim obtido foi, então, aplicado à placa cromatográfica e a visualização, realizada por três diferentes pessoas. Tendo sido confirmado que a contaminação poderia ser detectada sem dúvida pelos três diferentes visualizadores, o nível testado foi então considerado como limite de detecção da metodologia para as condições experimentais e no tipo de matriz testada.

O limite de quantificação (LQ) para as aflatoxinas foi considerado como sendo 5 vezes o limite de detecção [5].

Para avaliação da exatidão da metodologia, testes de recuperação foram realizados. Os testes de recuperação foram realizados utilizando-se amostras de produtos de amendoim que apresentaram ausência de contaminação. 
Estas amostras foram contaminadas com volume conhecido de padrão para aflatoxinas e, em seguida, realizou-se a extração e a quantificação destas.

A repetibilidade do procedimento analítico foi avaliada pelo cálculo do desvio padrão relativo dos resultados de quantificação do extrato de três amostras adicionadas de mesma quantidade de padrão de aflatoxinas.

Os padrões de aflatoxinas utilizados foram preparados e checados quanto à sua concentração, conforme procedimentos recomendados pelo método 971.22 da Association of Official Analytical Chemists - A.O.A.C. [1].

\section{3 - RESULTADOS E DISCUSSÃO}

Os testes da performance analítica da metodologia, utilizando cromatografia bidimensional, realizados como descritos, mostraram que o limite de detecção para cada uma das aflatoxinas B1, B2, G1 e G2 foi de 0,2 ng/g e o limite de quantificação foi de $1 \mathrm{ng} / \mathrm{g}$. A repetibilidade verificada no nível de quantificação mostrou valores de variabilidade (desvio padrão relativo), como mostrado na Tabela 1, inferiores a $30 \%$, como recomendado [19]. A exatidão, mensurada pelos índices de recuperação, como mostrado na Tabela 2 , apresentou também valores satisfatórios, ou seja, para os níveis de adição utilizados, recuperações superiores a $70 \%$ e inferiores a $110 \%$ [5].

A observação geral dos resultados, apresentados na Tabela 3 e 4, sem considerar o tipo de produto, mostra que 75 (25\%) das 297 embalagens amostradas apresentaram algum nível de contaminação, sendo que 20 [7\%] destas estavam com contaminação acima de 20 ng/g, limite máximo permitido, estabelecido pela Agência Nacional de Vigilância Sanitária (ANVISA), para contaminação de produtos de amendoim no Brasil [2]. Levantamentos anteriores realizados no Brasil [3, 15, 16] mostraram, normalmente, freqüências e níveis mais elevados. Isto se deve, provavelmente, a uma melhora na qualidade da matéria-prima utilizada, resultado de campanhas de melhoria dos produtos de amendoim existentes e implantação de legislações específicas sobre o problema. Entretanto, a possibilidade de ser uma situação restrita deve ser considerada e, assim, somente o monitoramento por outros períodos poderá confirmar esta melhora como algo permanente.

TABELA 1 - Coeficiente de variabilidade ou desvio padrão relativo observado para o teste de quantificação no nível de contaminação de $1 \mathrm{ng} / \mathrm{g}$ para metodologia utilizada na análise de produtos de amendoim.

\begin{tabular}{cccccc}
\hline \multicolumn{7}{c}{ Derivados de Amendoim } \\
Aflatoxina & $\mathbf{B}_{\mathbf{1}}$ & $\mathbf{B}_{\mathbf{2}}$ & $\mathbf{G}_{\mathbf{1}}$ & $\mathbf{G}_{\mathbf{2}}$ & Total \\
\hline Amostra* $^{*}$ & & & & & \\
1 & 0,9 & 0,8 & 1,1 & 0,6 & 3,4 \\
2 & 1,3 & 0,8 & 0,9 & 0,8 & 3,8 \\
3 & 0,9 & 0,8 & 0,9 & 0,7 & 3,5 \\
CV\% & 24,8 & 0,7 & 9,2 & 13,2 & 9,0 \\
\hline
\end{tabular}

Amostras 1, 2 e 3 são repetições de extrações e quantificações de amostras adicionadas de $1 \mathrm{ng} / \mathrm{g}$ para cada uma das aflatoxinas B1, B2, G1 e G2.
TABELA 2 - Intervalo para os valores (\%) de recuperação e média obtida entre determinações para aflatoxinas nos produtos estudados.

\begin{tabular}{ccl}
\hline Aflatoxina & Amendoim japonês & \multicolumn{1}{c}{ Paçoca } \\
\hline B1 & $78-95(86)$ & $83-110(92)$ \\
B2 & $70-89(80)$ & $68-97(78)$ \\
G1 & $82-100(92)$ & $78-110(92)$ \\
G2 & $70-100(88)$ & $88-97(88)$ \\
\hline
\end{tabular}

* nível de contaminação de 2,5 ppb para B1 e G1 e 1,5 ppb para B2 e G2, repectivamente.

Considerando a distribuição da ocorrência de contaminação entre todos os lotes amostrados, como mostrado nas Tabelas 3 e 4, a análise por tipo de produto mostra que entre os lotes de paçoca amostrados houve uma percentagem muito maior de embalagens com algum nível de contaminação (45\%) ou acima do limite brasileiro (13\%), comparado ao amendoim japonês que apresentou $9 \%$ e $1 \%$, respectivamente. Esta diferença de distribuição fica muito mais expressiva considerando-se a ocorrência de contaminação entre embalagens somente dos lotes que apresentaram alguma contaminação, como mostrado na Tabela 5. Assim, nos lotes de paçoca que apresentavam a ocorrência de contaminação, normalmente esta ocorrência era observada em $86 \%$ das embalagens amostradas, mas, nos lotes de amendoim japonês contaminados, a ocorrência foi observada na média somente em $13 \%$ das embalagens amostradas.

Visando avaliar a distribuição dos níveis de contaminação entre embalagens dos lotes, foi calculado o coeficiente de variação (Tabela 3 e 4) entre eles. Assim, para os lotes de paçoca, o coeficiente de variação médio foi de $75 \%$, apresentando valores de $13 \%$ a $198 \%$. Já os lotes de amendoim apresentaram um coeficiente médio de $294 \%$ e valores variando de $200 \%$ a $441 \%$. Assim, observa-se que, apesar da contaminação apresentar-se heterogênea entre as embalagens de paçoca, o grau de heterogeneidade, mensurado pelo coeficiente de variação, foi muito mais elevado entre as embalagens dos lotes de amendoim japonês, que foi o único a apresentar em um lote embalagens com níveis inferiores e superiores ao limite brasileiro.

As determinações de atividade de água do conteúdo das embalagens, apresentadas nas Tabelas 3 e 4, mostram que a maioria das embalagens dos produtos não ofereciam condições de crescimento fúngico e produção de aflatoxinas, no momento da amostragem, pois, segundo TANIWAKI \& SILVA [1996] [18], para crescimento e produção, são necessários valores de Aa superiores a 0,65. Apenas um lote de paçoca apresentou as embalagens com valores propícios ao crescimento fúngico, aproximadamente 0,75 , mostrando que, embora não seja freqüente, existe a possibilidade de crescimento fúngico no produto paçoca no local de comercialização. Entretanto, não se pode inferir sobre a influência deste parâmetro para os demais lotes no decorrer de todo período, entre a produção e exposição à venda, pois não houve o monitoramento da Aa durante esse período. 
TABELA 3 - Perfil de contaminação (ng/g) com aflatoxinas (B1 + B2 + G1 + G2) entre embalagens de lotes comerciais de paçoca amostrados.

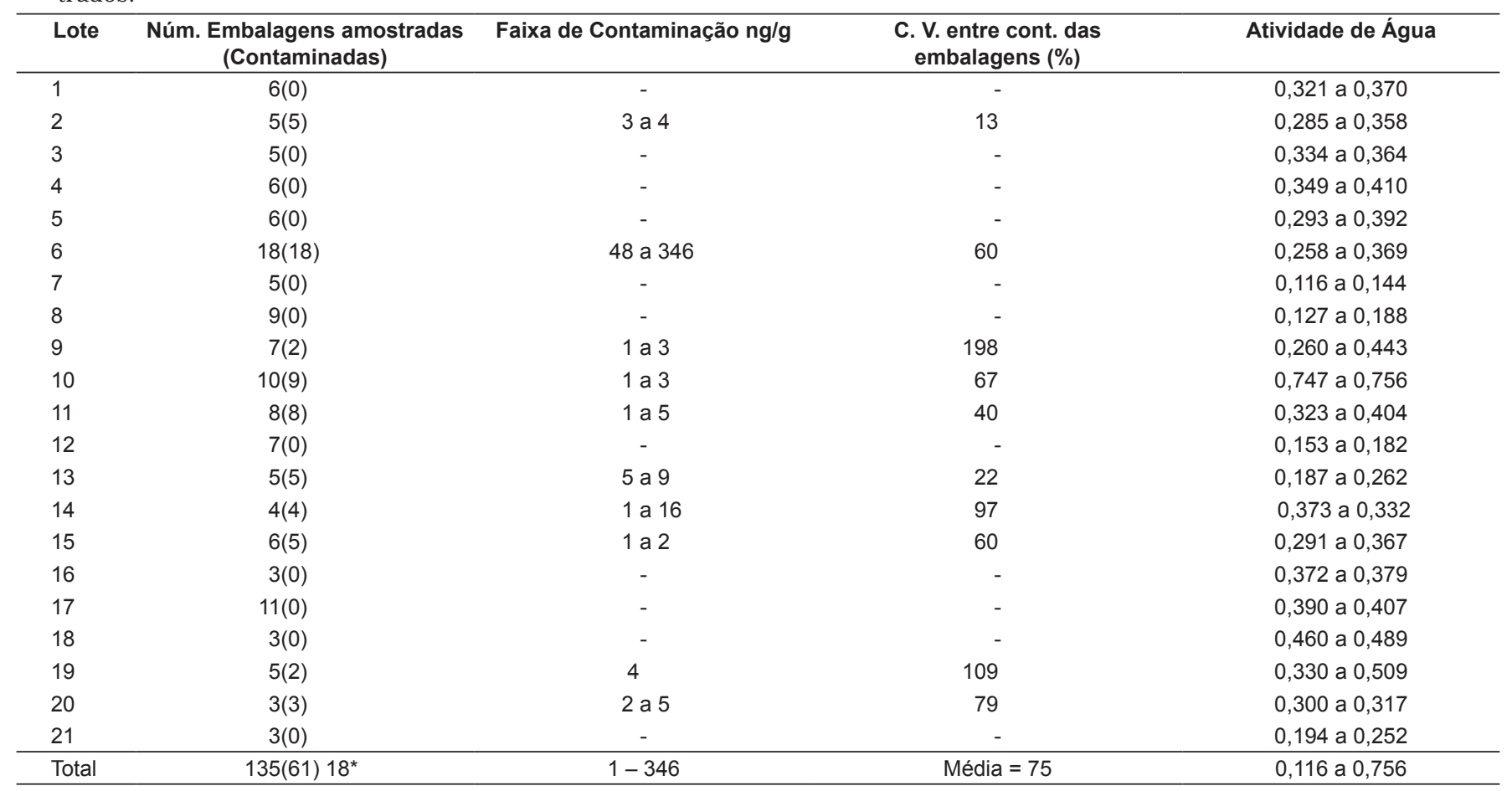

*número de amostras que apresentaram contaminação acima de 20 ng/g (B1 + B2 + G1 + G2).

TABELA 4 - Perfil de contaminação (ng/g) com aflatoxinas (B1 + B2 + G1 + G2) entre embalagens de lotes comerciais de amendoim japonês amostrados.

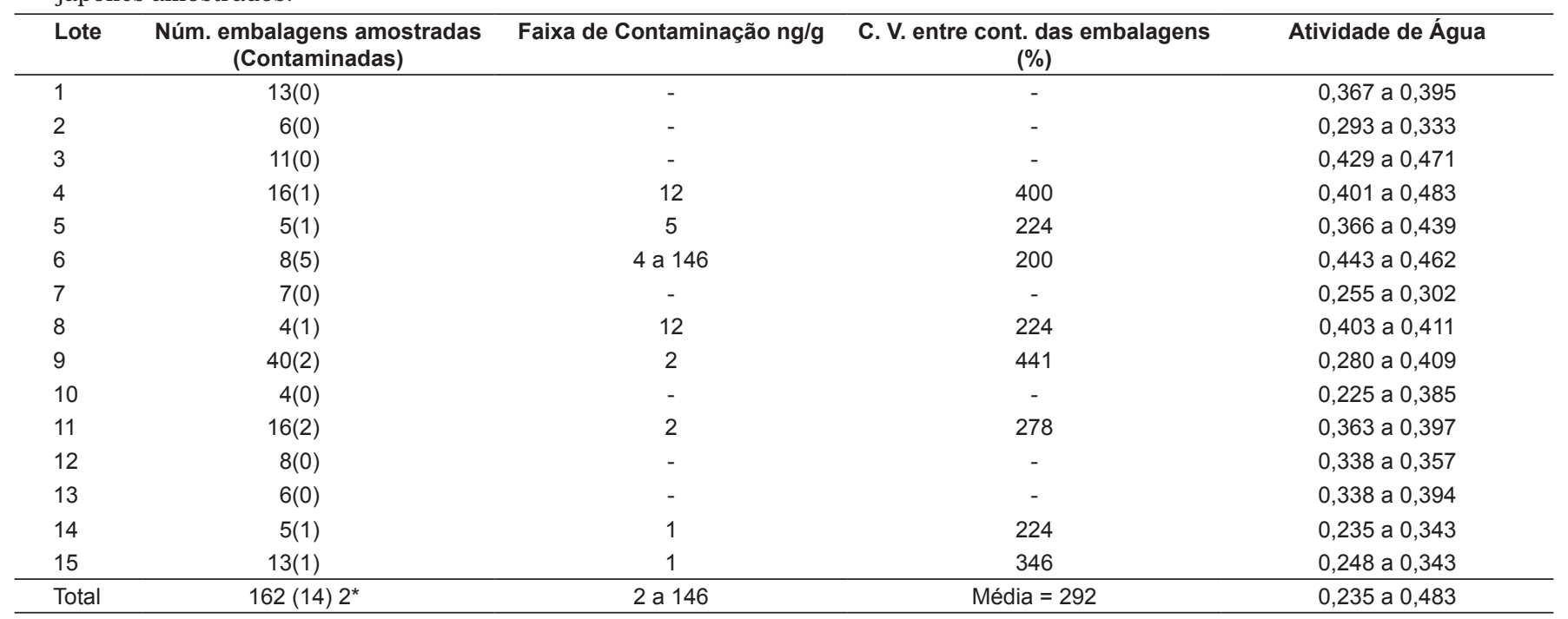

*número de amostras que apresentaram contaminação acima de 20 ng/g (B1 + B2 + G1 + G2).

\section{4 - CONCLUSÕES}

Os dados da distribuição da ocorrência e dos níveis de contaminação sugerem que os procedimentos de amostragem, visando à detecção de aflatoxinas em produtos processados, sempre estarão associando um grau de incerteza muito elevado quanto à presença ou não e quanto ao nível médio de contaminação de um lote de produto processado. Entretanto, para melhorá-los devem ser con- sideradas as diferenças existentes entre os produtos com relação ao processamento ou não dos grãos que constituem sua matéria-prima, pois, em lotes de produtos em que a matéria-prima foi triturada ou moída, como por exemplo, o doce de amendoim do tipo paçoca, a distribuição da ocorrência e dos níveis mostrou um grau bem mais elevado de homogeneidade, quando comparado ao amendoim japonês que mantém a integridade da matéria-prima durante o seu processo de fabricação. 
TABELA 5 - Distribuição da contaminação entre embalagens dos lotes contaminados.

\begin{tabular}{|c|c|c|c|}
\hline Produto & $\begin{array}{l}\text { Núm. de embalagens do lote } \\
\text { exposto }\end{array}$ & $\begin{array}{c}\text { Núm. de embalagens } \\
\text { contaminadas }\end{array}$ & $\begin{array}{c}\text { Percentagem de embalagens } \\
\text { contaminadas }\end{array}$ \\
\hline Paçoca & 5 & 5 & 100 \\
\hline Paçoca & 18 & 18 & 100 \\
\hline Paçoca & 7 & 2 & 26 \\
\hline Paçoca & 10 & 9 & 90 \\
\hline Paçoca & 8 & 8 & 100 \\
\hline Paçoca & 4 & 4 & 100 \\
\hline Paçoca & 6 & 5 & 83 \\
\hline Paçoca & 5 & 2 & 40 \\
\hline Paçoca & 5 & 5 & 100 \\
\hline Paçoca & 3 & 3 & 100 \\
\hline Média & 71 & 61 & 86 \\
\hline Amendoim japonês & 16 & 1 & 6 \\
\hline Amendoim japonês & 5 & 1 & 20 \\
\hline Amendoim japonês & 8 & 5 & 63 \\
\hline Amendoim japonês & 4 & 1 & 25 \\
\hline Amendoim japonês & 40 & 2 & 5 \\
\hline Amendoim japonês & 5 & 1 & 20 \\
\hline Amendoim japonês & 16 & 2 & 13 \\
\hline Amendoim japonês & 13 & 1 & 8 \\
\hline Média & 107 & 14 & 13 \\
\hline
\end{tabular}

Estes dados também reforçam a importância do adequado preparo das amostras compostas de diferentes embalagens de produtos comerciais, no que se refere à moagem e homogeneização do material antes da subtração da amostra analítica, principalmente quando o produto preserva a integridade dos grãos da matéria-prima.

Para o produto paçoca, apesar de não ser freqüente, existe a possibilidade de ocorrerem condições de atividade de água propícias ao crescimento fúngico no ponto de venda.

\section{5 - REFERÊNCIAS BIBLIOGRÁFICAS}

[1] ASSOCIATION OF OFFICIAL ANALYTICAL CHEMISTS. Official methods of analysis, $16 \mathrm{ed}$. Arlington, 1995 v. 1.

[2] BRASIL, Ministério da Saúde. Agência Nacional de Vigilância Sanitária, Resolução RDC n 274, de 15 de outubro de 2002, publicada no Diário Oficial da União, de 16/10/2002. In: <http://e-legis.bvs.br/leisref/public/ home.php>. Acesso em 10 de Fevereiro de 2005.

[3] CALDAS, E. D.; SILVA, S. C.; OLIVEIRA, J. N. Aflatoxinas e ocratoxina A em alimentos e riscos a saúde humana. Revista de Saúde Pública, v. 36, n. 3, p. 319-23, 2002.

[4] CAST (Council for Agricultural Science and Technology) - Mycotoxins: risks in plant, animal and human systems. Ames, 2003. 199 p. (Task Force Report, n. 139).

[5] CODEX ALIMENTARIUS COMMISSION. Criteria for evaluating acceptable methods of analysis for Codex purposes, Codex Committee on Methods of Analysis and Sampling, Documento CX/MAS 98/5, 1998.

[6] COKER, R. D.; NAGLER, M. J.; BLUNDEN, G.; SHARKEY, A. J.; DEFIZE, P. R.; DERKSEN, G. B.; WHITAKER, T.
B. Design of sampling plans for mycotoxins in foods and feeds. Natural Toxins, v. 3, p. 257-262, 1995.

[7] COMMISSION DIRECTIVE 401/2006 of 23 February 2006. Official Journal of the European Communities, 9.3.2006

[8] De VRIES, H. R. et al. Aflatoxin excretion in children with kwshiorkor or marasmic kwashiorkor - a clinical investigation. Mycopathologia, v. 110, p. 1-9, 1990.

[9] DICKENS, J. W.; WHITAKER, T. B. In: COLE, R.J. Modern methods in the analysis and structural elucidation of mycotoxins. Orlando, Academic Press Inc., 1986. Cap. 2, p. 29-47.

[10] FAO. Reglamentos a nivel mundial para las micotoxinas en los alimentos y las raciones en el año 2003. Roma, 2004. 171 p. (Estudio FAO Alimentacion y Nutricion n. 81).

[11] HENDRICKSE, R. G. Kwashiorkor the hypothesis that incriminates aflatoxins. Pediatrics, v. 88, p. 376-379, 1991.

[12] IARC. Monographs on the evaluation of carcinogenic risks to humans. Some naturally occurring substances: food items and constituents, heterocyclic aromatic amines and mycotoxins. 1993 Lyon. v. 56. $397 \mathrm{p}$.

[13] PEERS, F. G.; BOSCH, X.; KALDOR, J.; LINSELL, C. A.; PLUUMEN, M. Aflatoxin exposure, hepatitis B virus infection and liver cancer in Swaziland. International Journal of Cancer, v. 39, n. 5, p. 545-553, 1987.

[14] POHLAND, A. E. Mycotoxins in review. Food Additives and Contaminants, v. 10, p. 17-28, 1993.

[15] SABINO, M.; MILANEZ, T. V.; LAMARDO, L. C. A.; INOMATA, E. I.; ZORZETTO, M. A.; NAVAS, S. A.; STOFER, M. Occurrence of aflatoxins in peanuts and peanut products consumed in the state of São Paulo/Brazil 
from 1995 to 1997. Revista de Microbiologia, v. 30, p. 85-88, 1999.

[16] SABINO, M.; ZORZETTO, M. A. P.; PEDROSO, M. O.; MILANEZ, T. V. Incidênciade aflatoxinas em amendoim e produtos derivados consumidos na cidade de São Paulo, no período de 1980 a 1987. Revista do Instituto Adolfo Lutz, v. 49, p. 41-44, 1989.

[17] SOARES, L. M. V.; RODRIGUEZ-AMAYA, D. B. Survey of aflatoxin, ochratoxin A, zearalenone and sterigmatocystin in some Brazilian food by using multitoxin thin-layer chromatographic method. Journal of the Association of Official Analytical Chemists, v. 72 , p. 22-36, 1989.

[18] TANIWAKI, M. H.; SILVA, N. Fungos deterioradores de alimentos ocorrência e detecção. Campinas: ITAL, 1996.
[19] TAYLOR, J. K. Quality Assurance of Chemical Measurements, Chelsea: Lewis Publishers, 1987. Cap. 9: Principles of Measurement, p. 75-92.

[20] WHITAKER, T. B.; DICKENS, J. W.; MONROE, R. J. Variability of aflatoxin test results. Journal of the American Oil Chemists'Society, v. 51, p. 214-218, 1974.

[21] YEH, F. S.; YU, M.; MO, C. C.; LUO, S.; TONG, M. J.; HENDERSON, B.E. Hepatitis B virus, aflatoxin and hepatocellular carcinoma in southern Guangxi, China. Cancer Research, v. 49, p. 2506-2509, 1989.

\section{6 - AGRADECIMENTOS}

À Fundação de Amparo à Pesquisa do Estado de São Paulo pelo financiamento desta pesquisa por meio do auxílio pesquisa 02/02598-6. 